\title{
Risky Sexual Behavior and Its Determinants among Orphan and Vulnerable Children in Addis Ababa, Ethiopia
}

\author{
Ayana Chimdessa Fite' ${ }^{1}$ Amsale Cherie ${ }^{2 *}$ \\ ${ }^{1}$ College of Health Science, Debre Berhan University, Debre Berhan, Ethiopia \\ ${ }^{2}$ Department of Nursing and Midwifery, College of Health Sciences, Addis Ababa University, Addis Ababa, Ethiopia \\ Email: ayanayoom@gmail.com, ${ }^{*}$ amsalec2002@yahoo.com
}

How to cite this paper: Fite, A.C. and Cherie, A. (2016) Risky Sexual Behavior and Its Determinants among Orphan and Vulnerable Children in Addis Ababa, Ethiopia. World Journal of AIDS, 6, 111-122. http://dx.doi.org/10.4236/wja.2016.64015

Received: August 10, 2016

Accepted: November 1, 2016

Published: November 4, 2016

Copyright $\odot 2016$ by authors and Scientific Research Publishing Inc. This work is licensed under the Creative Commons Attribution International License (CC BY 4.0).

http://creativecommons.org/licenses/by/4.0/ (c) † Open Access

\begin{abstract}
Back Ground: Risky sexual behavior among orphans and vulnerable children and its associated physical, psychological and social consequences is becoming a major public health concern globally. Objectives: To assess the prevalence of risky sexual behavior and its determinants among orphan and vulnerable children in Addis Ababa. Methodology: A community based cross sectional study was conducted on three support and care giving organizations for orphans and vulnerable children in Addis Ababa, Ethiopia from March to June 2014. A total of 422 orphan and vulnerable children were selected using systematic sampling. Data were collected using pre tested self-administered questionnaire. Logistic regression was used to analyze the data. Result: A total of 407 (96.4\%) respondents participated in this study. Among them $112(27.5 \%)$ had sexual intercourse in their life time, of these 50 (44.6\%) started sex before the age of 15, 94 (83.9\%) had forced sex, 84 (75.0\%) had multiple sexual partners, only $16(14.3 \%)$ used condom the first time they had sex and 96 (85.7\%) participated in transactional sex. Females were about 3.25 (2.67 - 7.3) times more likely to engage in risky sexual behavior than male respondents, double orphans had 4.32 (2.45 - 9.54) odds of risky sexual behavior compared to their counterparts. Those respondents who had knowledge of HIV transmission and prevention were less likely to be involved in risky sexual behavior 0.58 (0.41 - 0.93). Conclusion: Orphan and vulnerable children are at a higher likelihood of risky sexual behavior. Intervention targeted at multilevel such as orphan survival training, assertive communication skills, sexuality education and education about HIV risk perception, physical, psychological and human right protection, social support, and economic access for basic needs need to be given consideration.
\end{abstract}




\section{Keywords}

Orphan, Vulnerable Children, Risky Sexual Behavior, Forced Sex, Transactional Sex, Addis Ababa

\section{Introduction}

The increased sexual risk among orphans and vulnerable children (OVC) and its associated physical, psychological and social consequences is becoming a major public health concern throughout the world. An estimated 143,000,000 children worldwide had been orphaned. The number of orphan and vulnerable children is increasing in Sub-Saharan African countries. Studies showed that $12 \%$ of African children lost one or both parents [1]. Orphaned children are at an elevated sexual risk which raises the threat of contracting HIV/AIDS and other sexually transmitted infections [2].

HIV/AIDS is a global challenge affecting people in their reproductive age and its effect on children, family and community is alarming. Globally, an estimated 35.3 (32.2 38.8) million people were living with HIV in 2012. There were 2.3 (1.9 - 2.7) million new HIV infections in the world [3]. In 2012 alone, there were 1.4 million adult deaths from HIV/AIDS which resulted in increasing number of orphans. Studies indicated that there were 17.3 million orphans due to HIV/AIDS globally. Out of these majority of OVC (90\%) live in Sub-Saharan Africa and Southern and Southeastern Asia [3].

There are an estimated 5.4 million orphans in Ethiopia. According to 2007 census conducted in Ethiopia there were 145,052 orphans in Addis Ababa city administration, out of these 29,264 were double orphans, most of them are orphaned due to HIV/AIDS [4] [5] [6].

Orphan and vulnerable children may fall prey to sexual coercion, exploitation and abuse and may be forced to engage in high risk behavior that may predispose them to the risk of unwanted pregnancy and contracting HIV and other STIs [1] [7] [8] [9] [10]. A study from South Africa found that $14-18$ year-old orphans were 1.38 times more likely than non-orphans to have engaged in risky sex [11]. Studies identified higher rates of HIV among orphans [11] [12]. OVC have been found to have a higher likelihood of being sexually active, initiate sex at an earlier age, and have unprotected sex and multiple partners [13] [14] [15] [16].

Understanding the magnitude of risky sexual behavior and exploring its underpinning factors is pivotal to address the needs of orphans and vulnerable children and mitigating the negative outcomes. However, there is paucity of information in this regard in Ethiopia. Therefore, it is the purpose of this study to assess the sexual practices as well as its associated factors among OVC in Addis Ababa, Ethiopia.

\section{Methods and Materials}

The study was conducted in Addis Ababa, the Capital City of Ethiopia using a crosssectional study design. All orphan and vulnerable children who are between $13-18$ 
years of age and who get community based care from three organizations: HIV/AIDS prevention and control office (HAPCO), save the children and parents and children together (Pact) were selected by using systematic sampling. The sample size was determined by considering prevalence of risky sexual practice among OVC 50\%, 95\% confidence Interval, a $5 \%$ margin of error $(\mathrm{d}=0.05)$ and a $10 \%$ allowance for non-response rate. On the basis of this the calculated sample size was 422 . Then the sample size was proportionately allocated based on the number of OVC getting support in the three organizations. On the basis of this 26 were taken from HAPCO, 45 from save the children and 351 from Pact.

A closed ended questionnaire was used for data collection. The questionnaire was adapted from previous literature [17]. The questionnaire was prepared in English and translated in to Amharic (the working language of Ethiopia), then back to English to check for consistency of meaning. Finally the Amharic version was used for data collection. The main components of the questionnaire are: socio-demographic characteristics and sexual practices.

Risky sexual practice behavior was assessed be asking 4 questions. Respondents who initiated sex before 15 years, not used condom consistently, having more than one partner or engaged in exchange sex were considered to be in risky sexual behavior. Those engaged in risky sexual behavior were coded as "1" and the remaining " 0 ".

A total of 17 questions were asked about knowledge of HIV transmission and prevention. Each question with a correct response was coded as "1" and incorrect answers "0". All scores of the respondents were summed up and the mean value was calculated. Respondents who got above or equal to the mean were considered knowledgeable and the rest not knowledgeable.

Six BSC nurses facilitated the data collection and two supervisors, who have experience on data collection supervision were recruited to supervise the data collection process and all of them took training for two days on the objective, procedure and content of the study.

The questionnaire was pre-tested to assess for clarity and sensitiveness of questions as well as understanding of the study subjects about the questions at Adama town, Oromia region. Based on the result of the pre-test, some modifications were made. Data were checked for completeness, by the supervisors and the principal investigator on daily basis.

Data were first interred to Epi Info 5.3.4 and exported to SPSS 20.0 Statistical package for analysis. Logistic regression was done to compute the association between dependent and independent variables and control for possible confounders.

Ethical clearance for the study was received from Addis Ababa University. A formal letter was written to all concerned authorities and permission was secured at all levels. Since the study subjects are younger than 18 years written assent was taken from study subjects and consent was taken from care givers or guardians after explaining the purpose and procedure of the study. Participation in the study was voluntary and information collected from the study subjects were kept strictly confidential. 


\section{Results}

A total of 422 orphan children were interviewed using standardized structured questionnaire and 407 (96.4\%) OVC were included in the analysis. Fifteen respondents were excluded from the analysis for gross incompleteness of responses.

\section{Socio Demographic Characteristics}

As it is shown in Table 1, 231 (56.8\%) of the respondents were female, and the mean age of respondents was $16+1.22$ years with minimum age of 13 and maximum age of 18. Out of the respondents 161 (39.8\%) were Amhara and 114 (28\%) of the OVC were Oromo by Ethnicity. Overall, 293 (72\%) of the respondents were orthodox Christians and $66(16.2 \%)$ were followers of Muslim religion. With regard to orphan status 203 (49.9\%) were double orphans.

Table 1. Socio-demographic characteristics of OVC in A.A, Ethiopia, $2014(\mathrm{n}=407)$.

\begin{tabular}{|c|c|c|c|}
\hline \multirow{2}{*}{ S. No. } & \multirow{2}{*}{ Characteristics } & \multicolumn{2}{|c|}{ Frequency } \\
\hline & & Number & $\%$ \\
\hline \multirow{3}{*}{1} & Sex & & \\
\hline & 1. Male & 176 & 43.2 \\
\hline & 2. Female & 231 & 56.8 \\
\hline \multirow{3}{*}{2} & Age & & \\
\hline & $1.13-15$ & 152 & 37.3 \\
\hline & 2. $16-18$ & 255 & 62.7 \\
\hline \multirow{6}{*}{3} & Religion & & \\
\hline & 1. Orthodox & 293 & 72 \\
\hline & 2. Protestant & 32 & 7.9 \\
\hline & 3. Catholic & 13 & 3.2 \\
\hline & 4. Muslim & 66 & 16.2 \\
\hline & 5. Others & 3 & 0.7 \\
\hline \multirow{7}{*}{4} & Ethnicity & & \\
\hline & 1. Amhara & 161 & 39.6 \\
\hline & 2. Oromo & 114 & 28 \\
\hline & 3. Tigre & 32 & 7.9 \\
\hline & 4. Gurage & 58 & 14.3 \\
\hline & 5. Silte & 25 & 6.1 \\
\hline & 6. Others & 17 & 4.2 \\
\hline \multirow{3}{*}{5} & Orphan status & & \\
\hline & Single & 204 & 50.1 \\
\hline & Double & 203 & 49.9 \\
\hline
\end{tabular}




\section{Sexual Practice of Orphan and Vulnerable Children}

Overall $112(27.5 \%)$ of the respondents had sexual intercourse in their life time, of these 50 (44.6\%) of the OVC started sex before the age of 15.

Of those who ever had sex 94 (83.9\%) of the OVC had forced first sex and only 16 (14.3\%) used condom the first time they had sex. The reasons for not using condom were $43(44.8 \%)$ refusal of partner, $40(41.7 \%)$ sex was not planned, $40(41.7 \%)$ too young to negotiate with partner, 38 (39.6\%) and fear of partner (Figure 1). Eighty four (75.0\%) of the OVC were involved in multiple sexual partner relationship. A total of 96 (85.7\%) of the OVC participated in transactional sex (see Table 2).
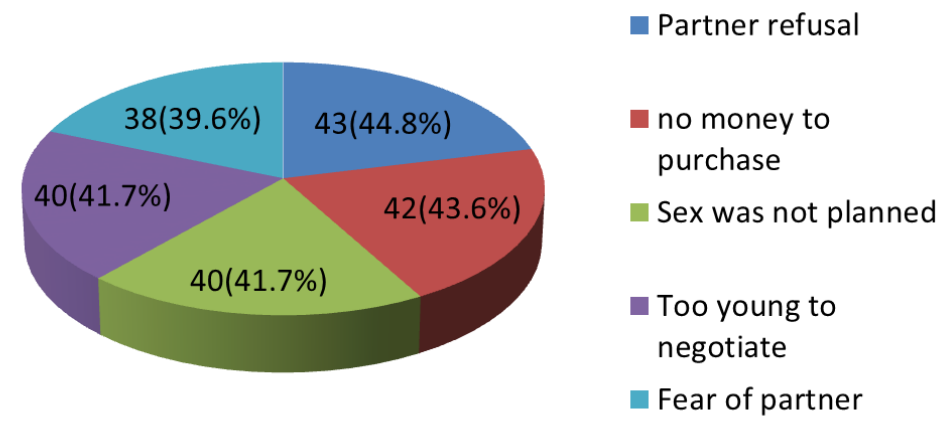

Figure 1. Reasons for not using condom among orphan and vulnerable children in Addis Ababa, Ethiopia 2014.

Table 2. Sexual practice among orphan and vulnerable children in Addis Ababa, Ethiopia 2014.

\begin{tabular}{|c|c|c|c|}
\hline S. No. & Characteristics & No & $\%$ \\
\hline & Ever had sexual intercourse & & \\
\hline \multirow[t]{3}{*}{1} & 1. Yes & 112 & 27.5 \\
\hline & 2. No & 295 & 72.5 \\
\hline & Age at first sex $=112$ & & \\
\hline \multirow[t]{3}{*}{2} & 1. Below 15 years & 49 & 43.7 \\
\hline & 2. $16-18$ years & 63 & 56.3 \\
\hline & Condom use at first sex & & \\
\hline \multirow[t]{3}{*}{3} & 1. Yes & 16 & 14.3 \\
\hline & 2. No & 96 & 85.7 \\
\hline & Sexual intercourse in the past 12 months & & \\
\hline \multirow[t]{3}{*}{4} & Yes & 94 & 83.9 \\
\hline & 2. No & 18 & 16.0 \\
\hline & Condom use in the past 12 months sex & & \\
\hline \multirow[t]{3}{*}{5} & 1. Yes & 36 & 32.1 \\
\hline & 2. No & 76 & 67.9 \\
\hline & Life time sexual partner $n=112$ & & \\
\hline \multirow{4}{*}{6} & One & 28 & 25.0 \\
\hline & $2-4$ & 53 & 47.3 \\
\hline & Above 4 & 31 & 27.7 \\
\hline & Forced sex & & \\
\hline \multirow[t]{3}{*}{7} & 1. Yes & 94 & 83.9 \\
\hline & 2. No & 18 & 16.1 \\
\hline & Exchange sex & & \\
\hline \multirow[t]{2}{*}{8} & 1. Yes & 96 & 85.7 \\
\hline & 2. No & 16 & 14.3 \\
\hline
\end{tabular}




\section{Predictors of Risky Sexual Behavior among OVC}

The multivariate analysis in Table 3 showed that female respondents were about 3.25 (2.67 - 7.3) more likely to engage in risky sexual behavior than male OVC. Double orphans had 4.32 (2.45 - 9.54) odds of risky sexual behavior compared to their counterparts. Those respondents who had knowledge of HIV/AIDS were less likely to be involved in risky sexual behavior $0.58(0.41-0.93)$ than their counterparts.

\section{Discussion}

This study assessed the sexual risk behaviors of OVC. The study findings showed that three quarter of sexually active OVCs were engaged in risky sexual behavior

This study showed that $43.7 \%$ of orphan adolescents engaged in early sexual intercourse In addition, consistent condom use among the study population in this study was low. It was only $14.3 \%$ of the sexually active study participants who used condom the first time they had sex. Three quarter of the sexually active respondents were involved in multiple sexual relationships. This confirms with studies from Africa were orphan status had a higher odds of engaging in risky sex compared to non-orphans [8] [12] [13] [14] [15] [16] [18]. OVC are at increased risk of risky sexual behavior because they may not have economic access, lack negotiation power, lack adequate daily subsistence, as well as the necessary physical and psychological protection, connectedness, and monitoring. Thus, this study illuminates interventions to address this gap.

OVC are highly vulnerable to sexual coercion, exploitation and abuse. This study

Table 3. Predictors of risky sexual behavior among orphan and vulnerable children in Addis Ababa, Ethiopia 2014.

\begin{tabular}{|c|c|c|c|c|}
\hline \multirow{2}{*}{ Variables } & \multicolumn{2}{|c|}{ Risky sexual behavior } & \multirow{2}{*}{ COR $(95 \% \mathrm{CI})$} & \multirow{2}{*}{ AOR $(95 \% \mathrm{CI})$} \\
\hline & Yes & No & & \\
\hline \multicolumn{5}{|l|}{ Sex } \\
\hline Female & 72 & 159 & $2.86(1.34-6.02)$ & $3.25(2.67-7.3)^{*}$ \\
\hline Male & 24 & 152 & 1.00 & 1.00 \\
\hline \multicolumn{5}{|c|}{ Orphan status } \\
\hline Double & 62 & 141 & $2.19(1.63-6.44)$ & $4.32(2.45-9.54)^{\star}$ \\
\hline Single & 34 & 170 & 1.00 & 1.00 \\
\hline \multicolumn{5}{|c|}{ Knowledge of HIV/AIDS } \\
\hline High & 39 & 178 & $0.51(0.32-0.89)$ & $0.58(0.41-0.93)^{*}$ \\
\hline Low & 57 & 133 & 1.00 & 1.00 \\
\hline \multicolumn{5}{|c|}{ Risk perception } \\
\hline Yes & 21 & 147 & $0.31(0.19-0.73)$ & $0.42(0.28-0.91)^{*}$ \\
\hline No & 75 & 164 & 1.00 & 1.00 \\
\hline
\end{tabular}


showed that $84 \%$ of OVC had forced sex in their life time. Corroborating with the findings of previous studies this study provided evidence that more than 3 in 4 of sexually active OVC were involved in transactional sex [9] [10] [19] [20] [21] [22]. This findings may be the tip of the iceberg as some of the perpetuators of OVC are the caregivers/guardians themselves. As a result, children may not have the confidence to report the incident fully. Sexual coercion and transactional sex has effect in the mental health of OVC and increases HIV and other STIs transmission as well as unwanted teen pregnancy.

Strong association was observed between being female, double orphan, and low knowledge about HIV transmission and prevention and risky sexual behavior [23]. Thus, these findings have implications for policy and programs in child protection and HIV and STIs prevention. Furthermore, this study signifies for focused interventions targeting OVC survival training, assertive communication skills, economic access for basic needs, family/guardian level interventions, sexuality education and social support.

The result of this study can be generalized to similar population as the study participants were randomly selected and adequate sample size was used. However, data were collected from self reports of the study participants and the study was a cross-sectional design and therefore we cannot infer temporal or causal relationships between orphan status and self-reported risk behavior.

\section{Conclusion}

This study shows that a significant number of OVC ever had sexual intercourse and the majority of those who had had sex didn't use condom regularly. OVC had early sexual debut, and more than three fourth of the sexually active respondents had forced sex in their life time. Similarly, greater than three fourth of those who ever had sex were involved in transactional sex. Moreover, females, double orphans, and low knowledge about HIV transmission and prevention were associated with risky sexual behavior. Thus, this study has implication for policy and programmes at various levels. There is a need for intervention focusing on OVC survival training, assertive communication skills, sexuality education and education about HIV risk perception. In addition, family/ guardian level as well as societal level interventions such as physical and psychological protection of OVC, social support, and guardian/care givers supervision and monitoring of children's whereabouts and economic access for basic needs. This study has implication also for the protection of human right of OVC.

\section{Competing Interest}

The authors declare that there is no competing interest.

\section{Authors' Contribution}

Both Ayana Chimdessa and Amsale Cherie involved from the inception of idea to the design analysis and interpretation of the study and preparation of the manuscript. Both authors have read and approved the final manuscript. 


\section{Acknowledgements}

The authors would like to heart fully thank the study participants who devoted their time to participate in the study and contribute their valuable response.

\section{References}

[1] UNAIDS (2010) Report on the Global AIDS Epidemic. UNAIDS, New York.

[2] Kathryn, W., et al. (2009) A Comparison of the Wellbeing of Orphans and Abandoned Children Ages 6 - 12 in Institutional and Community-Based Care Settings in 5 Less Wealthy Nations. PLoS One, 4, e8169. http://dx.doi.org/10.1371/journal.pone.0008169

[3] UNAIDS (2013) Report on the Global AIDS Epidemic. UNAIDS, New York.

[4] Federal Democratic Republic of Ethiopia (2011) Federal HIV/AIDS Prevention and Control Office.

[5] Ministry of Health, Ethiopia (2006) Disease Prevention and Control Department. AIDS in Ethiopia.

[6] Central Statistics Agency of Ethiopia (2007) 1994 Population and Housing Census. CSA, Addis Ababa.

[7] Glynn, J.R., Caraël, M., Auvert, B., et al. (2001) Why Do Young Women Have a Much Higher Prevalence of HIV Than Young Men? A Study in Kisumu, Kenya and Ndola, Zambia. AIDS, 15, S51-S60. http://dx.doi.org/10.1097/00002030-200108004-00006

[8] McGrath, N., Nyirenda, M., Hosegood, V., et al. (2009) Age at First Sex in Rural South Africa. Sexually Transmitted Infections, 85, i49-i55.

http://dx.doi.org/10.1136/sti.2008.033324

[9] Cote, A.M., Sobela, F., Dzokoto, A., et al. (2004) Transactional Sex Is the Driving Force in the Dynamics of HIV in Acra, Ghana. AIDS, 18, 917-925.

http://dx.doi.org/10.1097/00002030-200404090-00009

[10] Cluver, L., Orkin, M., Mark Boyes, M., Gardner, F. and Meinck, F (2011) Transactional Sex amongst AIDS-Orphaned and AIDS-Affected Adolescents Predicted by Abuse and Extreme Poverty. JAIDS Journal of Acquired Immune Deficiency Syndromes, 58, 336-343. http://dx.doi.org/10.1097/QAI.0b013e31822f0d82

[11] Operario, D., Pettifor, A., Cluver, L., MacPhail, C. and Rees, H. (2007) Prevalence of Parental Death among Young People in South Africa and Risk for HIV Infection. Journal of Acquired Immune Deficiency Syndromes, 44, 93-98. http://dx.doi.org/10.1097/01.qai.0000243126.75153.3c

[12] Pettifor, A., Rees, H., Kleinschmidt, I., et al. (2003) Young People's Sexual Health in South Africa: HIV Prevalence and Sexual Behaviors from a Nationally Representative Household Survey. AIDS, 19, 1525-1534. http://dx.doi.org/10.1097/01.aids.0000183129.16830.06

[13] Gregson, S., Nyamukapa, C.A., Garnett, G.P., et al. (2005) HIV Infection and Reproductive Health in Teenage Women Orphaned and Made Vulnerable by AIDS in Zimbabwe. AIDS Care, 17, 785-794. http://dx.doi.org/10.1080/09540120500258029

[14] Palermo, T. and Peterman, A. (2009) Are Female Orphans at Risk for Early Marriage, Early Sexual Debut, and Teen Pregnancy? Evidence from Sub-Saharan Africa. Studies in Family Planning, 40, 101-112. http://dx.doi.org/10.1111/j.1728-4465.2009.00193.x

[15] Thurman, T.R., Brown, L., Richter, L., et al. (2006) Sexual Risk Behavior among South African Adolescents: Is Orphan Status a Factor? AIDS and Behavior, 10, 627-635. http://dx.doi.org/10.1007/s10461-006-9104-8 
[16] Juma, M., Alaii, J., Bartholomew, L.K., Askew, I. and Borne, B.V. (2012) Risky Sexual Behavior among Orphan and Non-Orphan Adolescents in Nyanza Province, Western Kenya. AIDS and Behavior, 17, 951-960. http://dx.doi.org/10.1007/s10461-012-0336-5

[17] CDC (2010) Youth Risk Behavior Surveillance-United States 2009. MMWR, 59, 1-142.

[18] Gueye, M., Castle, S. and Konate, M. (2001) Timing of First Intercourse among Malian Adolescents: Implications for Contraceptive Use. International Family Planning Perspectives, 27, 56-62. http://dx.doi.org/10.2307/2673815

[19] Cluver, L. and Operario, D. (2008) Inter-Generational Linkages of AIDS: Vulnerability of Orphaned Children for HIV Infection. IDS Bulletin, 39, 27-35. http://dx.doi.org/10.1111/j.1759-5436.2008.tb00492.x

[20] Bene, C. and Merten, S. (2008) Women and Fish-for-Sex: Transactional Sex, HIV/AIDS and Gender in African Fisheries. World Development, 36, 875-899.

http://dx.doi.org/10.1016/j.worlddev.2007.05.010

[21] Nkosana, J. and Rosenthal, D. (2007) The Dynamics of Intergenerational Sexual Relationships: The Experience of Schoolgirls in Botswana. Sex Health, 4, 181-187. http://dx.doi.org/10.1071/SH06070

[22] Hallman, K. (2004) Socioeconomic Disadvantage and Unsafe Sexual Behaviours of Young Women and Men in South Africa. Policy research Division Working Paper 190, Population Council, New York.

[23] Joseph, N., Laura, J., Sheila, H., Lisanne, B. and Nancy, B. (2012) Sexual Risk Behaviors among Youth Heads of Household in Gikongoro, South Province of Rwanda. BMC Public Health, 12, 225. http://dx.doi.org/10.1186/1471-2458-12-225 
Section 1. The following questions are about your background characteristics. Please indicate your response by circling the number of your choice or by writing your response in the space provided accordingly.

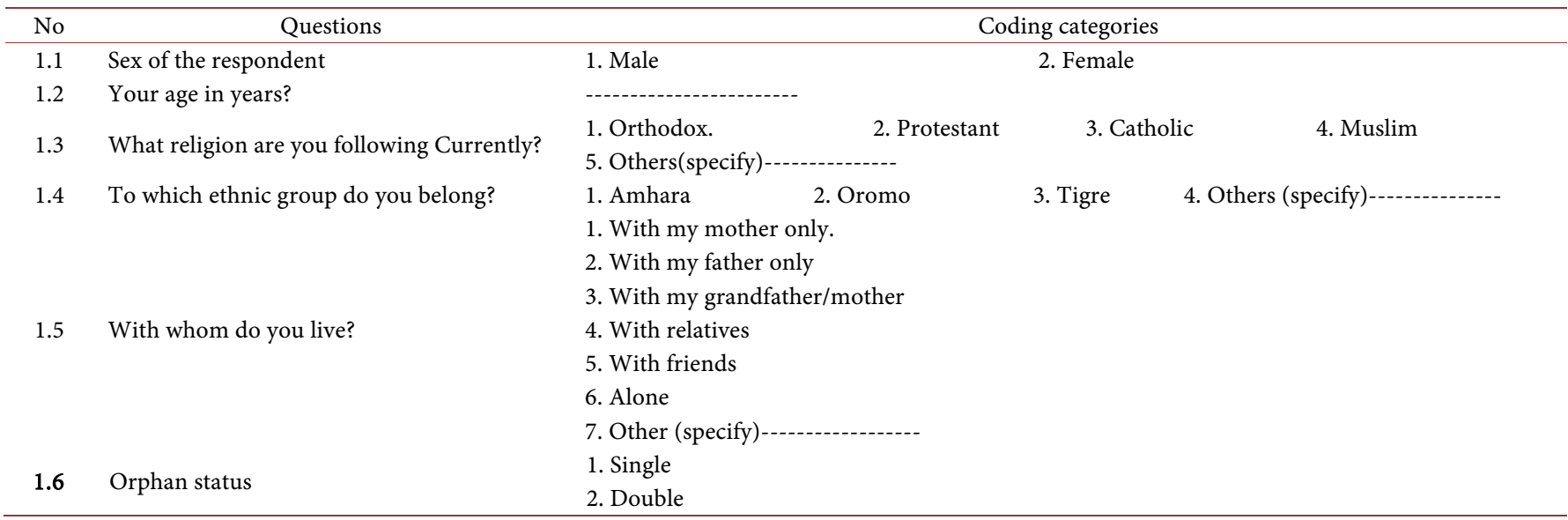

Section 2. Knowledge about HIV transmission and prevention. Please indicate your response by circling the number of your choice or by writing your response in the space provided accordingly.

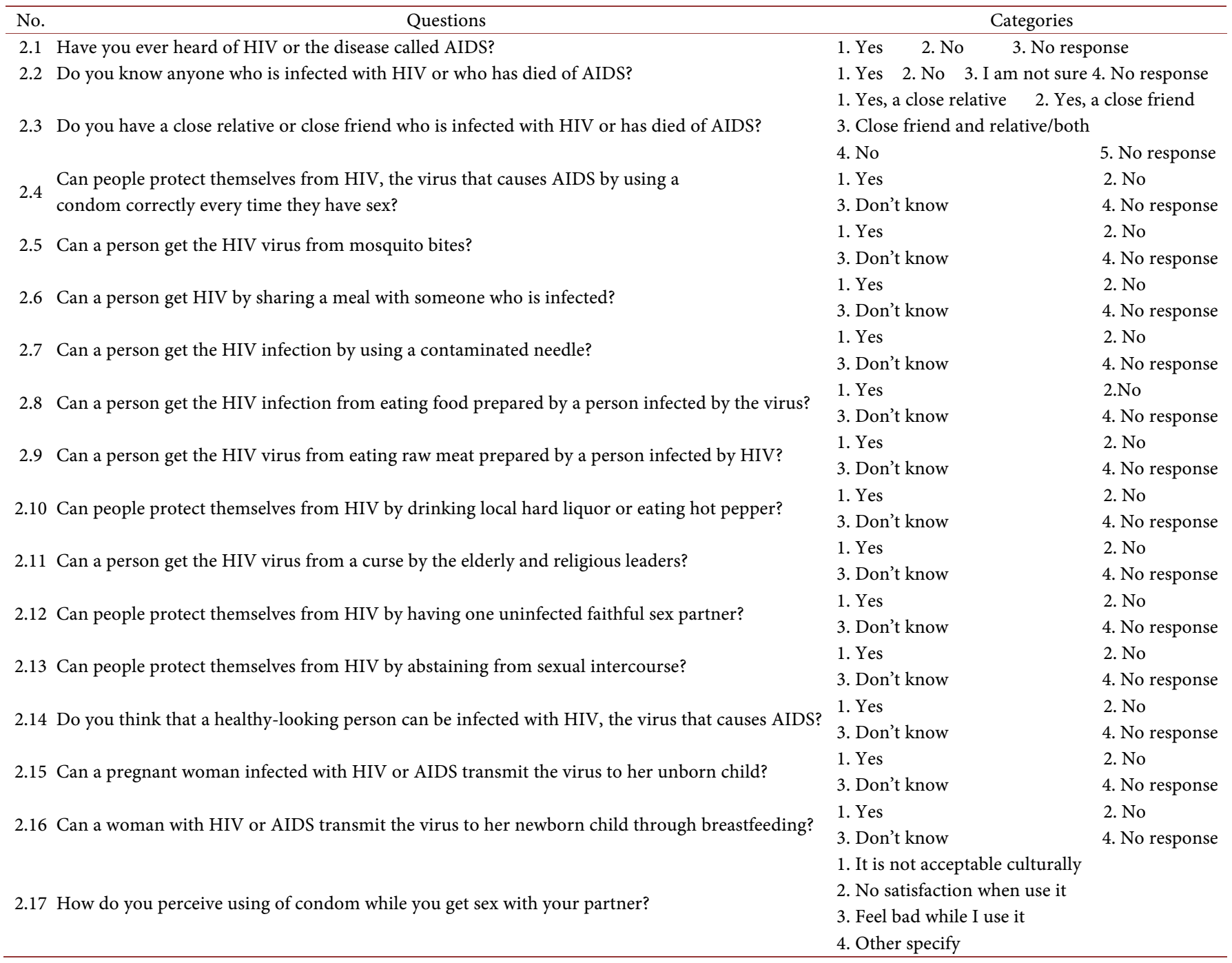


Section 3. Sexual behavior. Now we would like to ask you some questions about your sexual experience. We would like to remind you again that all of your responses will be kept confidential and your name is not attached to this questionnaire.

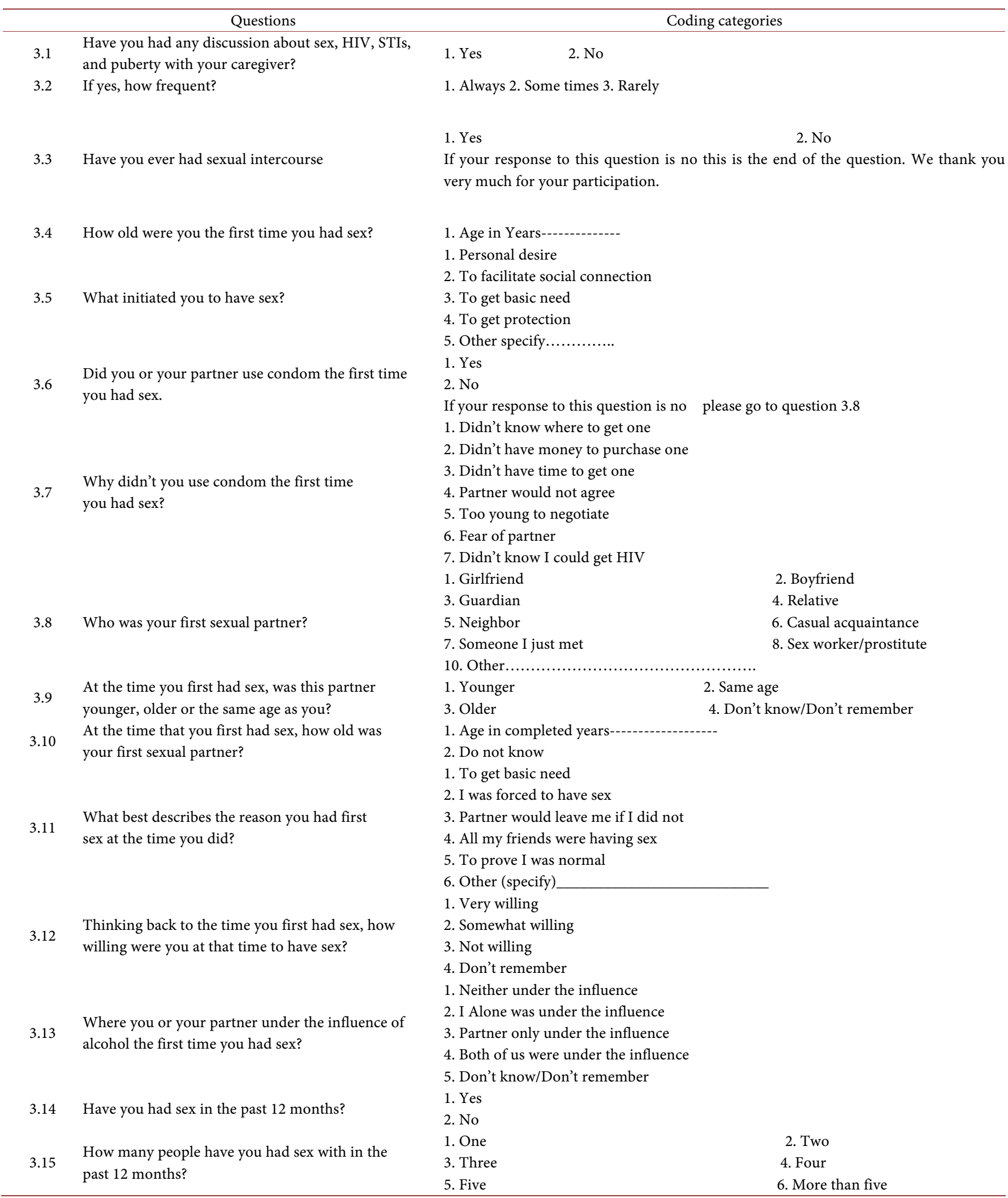


3.16 How frequently do you have sexual intercourse?

7. Don't know/Don't remember

1. At least once a week

2. At least once a month

3. A few times a year

4. No more than once a year

1. Yes

2. No

3. Don't remember

1. Never

2. Sometimes

How often do you or your partner(s) use condoms when you have sex?

3. Always

If never used condom in the past 12 months sex, why didn't you used condom?

What was your relationship to the person with whom you had sex in the past 12 months?

Was the person you had sex in the past 12 months younger, older or the same age as you?

1. Younger

3. Older

1. Yes
Have you ever been involved in exchange sex?

Have you ever been forced to have sex?

Forced sex is sex that you do not participate in at your will

Has anyone ever given you something to have sex with them?

What did they give you?

Have you ever been forced to have sex with a person you don't know?

Have you ever participated in sex work?
2. No

1. Yes

2. No

1. Yes

2. No

3. Don't remember

1. Money

3. School fees

2. Food

5. Shelter/Rent

4. Drugs

7. Ornaments

9. Other (specify)

1. Yes

6. Clothes

8. Help with Homework

3. No response

1. Yes
2. Same age

4. Don't know/Don't remember

\section{Scientific Research Publishing}

Submit or recommend next manuscript to SCIRP and we will provide best service for you:

Accepting pre-submission inquiries through Email, Facebook, LinkedIn, Twitter, etc.

A wide selection of journals (inclusive of 9 subjects, more than 200 journals)

Providing 24-hour high-quality service

User-friendly online submission system

Fair and swift peer-review system

Efficient typesetting and proofreading procedure

Display of the result of downloads and visits, as well as the number of cited articles

Maximum dissemination of your research work

Submit your manuscript at: http://papersubmission.scirp.org/

Or contact wja@scirp.org 